\title{
Area Under Urinary Excretion Rate Curve
}

National Cancer Institute

\section{Source}

National Cancer Institute. Area Under Urinary Excretion Rate Curve. NCI Thesaurus. Code C85537.

The area under the curve of a plot of drug concentration eliminated in urine against time. 